\title{
EFFECT OF VIRGIN HETEROPHASIC PP COPOLYMER CONTENT ON MOISTURE ABSORPTION, THERMAL AND MECHANICAL PROPERTIES OF RECYCLED POLYETHYLENE WOOD FLOUR COMPOSITES
}

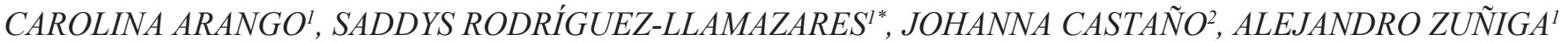 \\ ${ }^{1}$ Centro de Investigación de Polimeros Avanzados, Beltrán Mathieu 224, Concepción, Chile \\ ${ }^{2}$ Unidad de Desarrollo Tecnológico, Universidad de Concepción, Av. Cordillera $N^{\circ} 2634$ - Parque Industrial Coronel, Coronel, Chile
}

(Received: August 30, 2013 - Accepted: December 4, 2013)

\begin{abstract}
The effect of virgin heterophasic PP copolymer (vPP) content on moisture absorption, as well as on thermal and mechanical properties of recycled polyethylene/ wood flour composites was investigated. The polymer matrix of recycled post-consumed plastic waste (rPE) was composed of a matrix of LDPE and a part of PP. Wood flour of Pinus radiata was used as filler at a constant loading of $45 \mathrm{wt} . \%$. rPE/vPP blends and their composites were manufactured by melt blending, and then by injection molding. The morphology of the blends and composites was analyzed by means of scanning electron microscopy. The addition of vPP improved tensile and flexural moduli and flexural strength of wood plastic composites (WPC). The highest increase of these properties was observed for a WPC sample with a rPE/vPP ratio of 19. WPC made with higher virgin PP content (rPE/vPP ratio $=9$ and 5.7) showed lower increase of mechanical properties compared to polymer matrix and WrPE samples. The moisture uptake of WPC made of rPE/vPP blend was higher than those of rPE, and their mechanical properties were more adversely affected by immersion in water. TGA results indicate that rPE are thermally more stable than rPE/vPP blends. The incorporation of heterophasic PP copolymer into the recycled polymer matrix of WPC delays the starting of wood flour degradation.
\end{abstract}

Keywords: recycled LDPE-PP blend, wood plastic composite, mechanical properties, water absorption properties

\section{INTRODUCTION}

The recycling of consumed plastics is an attractive alternative to their disposal in landfills, reducing waste streams and their impact on the environment, and the consumption of virgin plastics. Recovery of plastics in Chile was only around 27,000 tons in $2009,4.3 \%$ of the total amount of plastics consumed..$^{1,2}$ One of the Chilean industries leading in this area, is the aquaculture industry, with $87 \%$ recovery of plastics in $2010 .{ }^{3}$ Most of the time this recycled plastic is reprocessed by down-cycling in order to make new articles of lower quality.

In particular, recycled low density polyethylene alone presents poor mechanical properties, and it is often mixed with other materials to be useful, such as virgin polyolefin and/or additives as fillers.

The presence of polypropylene (PP) in recycled polyethylene matrix is frequently found in plastic waste streams. ${ }^{4}$ These two polymers, although of similar chemical structure, are incompatible in the melting, and the blend exists as two distinct phases with very poor cohesion between them. The incompatibility of polyethylene/PP also contributes to the unsatisfactory mechanical properties of recycled polyethylene-PP (rPE-PP) blends. Therefore, compatibilizers are added during the reprocessing of rPE-PP blends, the most common are elastomeric block and random copolymers and terpolymers, such as ethylenepropylene and ethylene-propylene-diene elastomers. ${ }^{5,6}$ Graft copolymers has also been used as compatibilizers of rPE-PP blends. For example, by addition of PE-g-(2-methyl-1,3-butadiene) to blends composed of $90 \mathrm{wt} . \%$ of rPE and $10 \mathrm{wt} \%$ of recycled PP, a common composition of post-consumer plastic waste, the elongation at break and Charpy impact strength were improved. ${ }^{7}$ However, heterogeneity of the plastic mixture and the different degree of polymer degradation makes compatibilization of recycled plastics a difficult task. On the other hand, the selection of suitable compatibilizers for industrial applications is limited by economic constraints.

Mechanical properties of rPE-PP blends are improved by the addition of virgin polyolefin resin. Blom et al. ${ }^{8}$ reported that blends of virgin isotactic PP with a post-consumer plastic, consisting of an rPE-PP blend of (1 part of PP and 2 parts polyethylene), displayed higher impact strength than neat isotactic $\mathrm{PP}$, as well as neat post-consumer resin. This improvement on impact strength was not observed for virgin isotactic PP/high density polyethylene blends.

We have reported the preparation of wood plastic composites (WPC) from recycled plastic composed of a low density polyethylene matrix and a part of PP, and Pinus radiata wood flour. ${ }^{9}$ Small amounts of virgin homopolymer PP $(5,10$ and $15 \mathrm{wt} . \%)$ were used to improve the strength and processability of the melting. The addition of virgin homopolymer PP improved mechanical properties and reduced moisture absorption and swelling of the WPC manufactured from recycled plastic/virgin PP. Virgin homopolymer PP in WPC acted also as a reinforcing agent.
In this article, a commercial heterophasic PP copolymer with $12 \mathrm{wt} . \%$ of ethylene was incorporated into the recycled plastic WPC formulation to study how this affects the mechanical and thermal properties, as well as the water uptake behavior of these WPC. In particular, the use of this copolymer would not increase considerably the cost of this kind of WPC of rather low marketvalue, and could act as reinforcing agent and compatibilizer among recycled polyolefin, interacting with the PP part present in the rPE matrix. ${ }^{10}$

\section{EXPERIMENTAL}

\section{Materials}

The post-consumer plastic waste, composed of a matrix of LDPE and a part of PP (MFI $=0.85 \mathrm{~g} / 10 \mathrm{~min}$ at $230^{\circ} \mathrm{C}-2.16 \mathrm{~kg}$ ), was obtained mainly from packaging of the salmon farming industry, and was used as the main matrix, referred to hereinafter as rPE. The lignocelulosic filler was Pinus radiata D. Don wood flour with less than $2 \%$ humidity. Maleic anhydride grafted polypropylene with an acid value of $43 \mathrm{mg} \mathrm{KOH} / \mathrm{g}$ and $\mathrm{M}_{w}$ of 10,000 $\mathrm{g} / \mathrm{mol}$ (Licocene PP MA 6452 from Clariant) was used to enhance the wood flour/polymer matrix adhesion. As antioxidants Irgafos 168 and Irganox 1010 from Ciba (BASF) were used in a 2:1 ratio. A masterbatch of virgin LDPE and $20 \mathrm{wt} . \%$ antioxidants was prepared to be added to tested formulations. A commercial heterophasic PP copolymer, PCD 1214, from Petroquim S.A. (Chile) with $12 \mathrm{wt} . \%$ of ethylene comonomer content and MFI of $12 \mathrm{~g} / 10 \mathrm{~min}$ was employed as reinforcing agent for recycled polyolefin blends and WPC.

\section{Preparation of composites}

WPCs and blends were prepared in a co-rotating twin-screw extruder (TSA Industriale, Cernobbio, Italy). The barrel temperature of seven zones varied from $170^{\circ} \mathrm{C}$ (feeder) to $175^{\circ} \mathrm{C}, 175^{\circ} \mathrm{C}, 175^{\circ} \mathrm{C}, 175^{\circ} \mathrm{C}, 180^{\circ} \mathrm{C}$ and $185^{\circ} \mathrm{C}$ (heating zones) and the die temperature was above $190^{\circ} \mathrm{C}$. The extruder screw speed was set at $80 \mathrm{rpm}$ and average feed rate was $20 \mathrm{~kg} / \mathrm{h}$. More details of sample preparation were described elsewhere. ${ }^{9}$ The composition of the tested WPCs and blends, is summarized in Table I.

Before molding, pellets of tested samples were dried over night at $100^{\circ} \mathrm{C}$. Bars $\left(0.34 \times 1.25 \times 12.67 \mathrm{~cm}^{3}\right)$ and dumbbell tensile specimens were injection molded using Arburg 420C machine (Lossburg, Germany) for further characterization. The cylinder temperature was maintained constant at $190^{\circ} \mathrm{C}$

In order to determine the compatibility blends $\mathrm{rPE}$ and $\mathrm{rPE} / \mathrm{vPP}$ blends with different heterophasic PP copolymer content (see Table 1) were previously melt mixed in a batch mixer. The mixing speed, temperature and residence time were $60 \mathrm{rpm}, 190^{\circ} \mathrm{C}$ and $10 \mathrm{~min}$, respectively. Then, these samples were compression molded at $190^{\circ} \mathrm{C}$ for $4 \mathrm{~min}$, at a compressive load of 15 bars, in order to prepare films $(10 \times 10 \times 1 \mathrm{~mm})$ for their respective SEM characterization. 
Table I. Sample code and compositions of tested materials.

\begin{tabular}{|c|c|c|c|c|c|c|}
\hline \multirow{2}{*}{ Sample code } & \multicolumn{2}{|c|}{ Polymer matrix (wt.\%) } & \multirow{2}{*}{$\begin{array}{l}\mathrm{rPE} / \mathrm{vPP} \\
\text { ratio }\end{array}$} & \multirow{2}{*}{$\begin{array}{c}\text { WF } \\
\text { (wt.\%) }\end{array}$} & \multirow{2}{*}{$\begin{array}{c}\text { Licocene } \\
\text { (wt.\%) }\end{array}$} & \multirow{2}{*}{$\begin{array}{l}\text { Antioxidant } \\
\text { masterbatch } \\
\text { (wt.\%) }\end{array}$} \\
\hline & $\mathrm{rPE}$ & vPP & & & & \\
\hline $\mathrm{rPE}$ & 98.0 & - & - & - & - & 2.0 \\
\hline rPE/vPP-19 & 93.2 & 4.9 & 19.0 & - & - & 1.9 \\
\hline rPE/vPP-9 & 88.4 & 9.8 & 9.0 & - & - & 1.8 \\
\hline rPE/vPP-5.7 & 83.6 & 14.7 & 5.7 & - & - & 1.7 \\
\hline WrPE & 53.1 & - & - & 45.0 & 0.9 & 1.1 \\
\hline WrPE/vPP-19 & 50.5 & 2.7 & 19.0 & 45.0 & 0.9 & 1.0 \\
\hline WrPE/vPP-9 & 47.9 & 5.3 & 9.0 & 45.0 & 0.9 & 1.0 \\
\hline WrPE/vPP-5.7 & 45.2 & 8.0 & 5.7 & 45.0 & 0.9 & 0.9 \\
\hline
\end{tabular}

\section{Characterization}

\section{Mechanical testing}

Tensile and flexural tests were performed on a Karg Industrietechnik machine (Krailling, Germany) according to ASTM D638/97 and D790/97 standards, respectively. Prior testing, specimens were conditioned for $40 \mathrm{~h}$ at $23^{\circ} \mathrm{C}$ and $50 \%$ relative humidity. The flexural measurements were performed under a three-point bending configuration. The crosshead speed was set at 1.27 and $50 \mathrm{~mm} / \mathrm{min}$ for the flexural and tensile tests, respectively. The Young's modulus, strength, and elongation percentage at break were obtained from the stress-strain curves. At least 18 individual measurements were carried out for each formulation and mean values and standard deviations of tensile and flexural properties were reported. Collected data were evaluated with a oneway analysis of variance at the $95 \%$ confidence level. Differences among the mean values of variables were analyzed with Duncan's multiple-range test. The factors and levels used in the experiments are summarized in Table II. The statistical analyses were made with Statgraphics Centurion XV software, Statistical Graphics, Washington, United States.

Table II. Factor and level used in the experimental design.

\begin{tabular}{|c|c|c|c|c|}
\hline \multirow{2}{*}{ Factor } & \multicolumn{4}{|c|}{ Level } \\
\cline { 2 - 5 } & I & II & III & IV \\
\hline rPE/vPP ratio & 19.0 & 9.0 & 5.7 & Without vPP \\
\hline Wood flour & yes & no & - & - \\
\hline Water immersion & before & after & - & - \\
\hline
\end{tabular}

Morphological analysis of fractured surfaces

The fractured surfaces of the mechanical test specimens and films obtained by compression molded (sputtered with a gold coating of ca. $50 \mathrm{~nm}$ ) were observed at different magnifications, ranging from 100 to 3000 with a field emission scanning electron microscope (JEOL JSM 6380 LV, Tokyo, Japan) operated at 20 and $5 \mathrm{kV}$.

\section{Moisture uptake}

Specimens type bars $(0.34 \times 1.25 \times 12.67 \mathrm{~cm})$ obtained by injection molding were used in long-term immersion tests. Water absorption was determined according to ASTM D570-98. Ten specimens of each formulation were selected and dried for $24 \mathrm{~h}$ at $50^{\circ} \mathrm{C}$. The specimens were placed in distilled water and maintained at $23^{\circ} \mathrm{C}$ for 98 days. For each measurement, specimens were taken from the water and surface moisture was removed with absorbing paper. The sample weight was measured with $0.001 \mathrm{~g}$ precision at different times during time immersion. Specimens were considered substantial saturated when the increase in weight was less than $1 \%$ in three consecutive measurements. The percentage of water absorption was calculated according to the following expression:

$$
\text { Water absorption }(\%)=\frac{\text { wet weight }(\mathrm{g})-\text { oven-dry weight }(\mathrm{g})}{\text { oven-dry weight }(\mathrm{g})} \times 100
$$

\section{Thermal analysis}

Thermal stability of blends and WPCs was evaluated using a thermogravimetric analyzer NETZSCH 209 F3 TGA (Tarsus, Selb, Germany). Thermogravimetric (TGA) curves were recorded at $10^{\circ} \mathrm{C} / \mathrm{min}$, in a range between 30 and $640^{\circ} \mathrm{C}$, under nitrogen atmosphere $(20 \mathrm{~mL} / \mathrm{min})$.

\section{RESULTS AND DISCUSSION}

Exploratory studies to evaluate the compatibility of $\mathrm{rPE} /$ virgin heterophasic PP copolymer blends (rPE/vPP) with different heterophasic PP copolymer content were performed. Cryogenically fractured surfaces were prepared by means of compression-molding of samples and observed by SEM (see Figure 1). Micrographs of the fractured surface of rPE revealed a co-continuous morphology with droplets spread out in the rPE matrix. The dispersed droplets corresponded to recycled PP, the minority phase. rPE/ vPP blends also displayed phase separation, but the microstructural phase separation of rPE/vPP blends with $\mathrm{rPE} / \mathrm{vPP}$ ratio of 19 was finer and of better homogeneity than neat rPE. In addition, the size of virgin PP domains were more uniform for blends with 4.9 wt.\% of PP content (sample: rPE/vPP-19). Similar morphology has been reported by other authors ${ }^{7,11}$ for rPE-PP blends of $80 / 20$ and $90 / 10$ (PE/PP) with circa $5 \mathrm{wt} . \%$ of a compatibilizing agents, such as ethylene-propylene-diene monomer and ethylene-propylene monomer. In general, elastomers used as compatibilizer for polyolefin PE-rich blends have a high content of ethylene monomer. ${ }^{6}$

The domain size of virgin PP, the dispersed component, was larger for those $\mathrm{rPE} / \mathrm{vPP}$ blends with $\mathrm{rPE} / \mathrm{vPP}$ ratio $=5.7$, indicating a decrease in the compatibility by increasing content of virgin PP in the blend. This may be partly due to the self-association, which is more favorable than hetero-association when the content of virgin heterophasic PP copolymer is higher than 4.9 wt.\%. It is important to note that there was no difference in the morphology of compression-molded and injection-molded specimens.
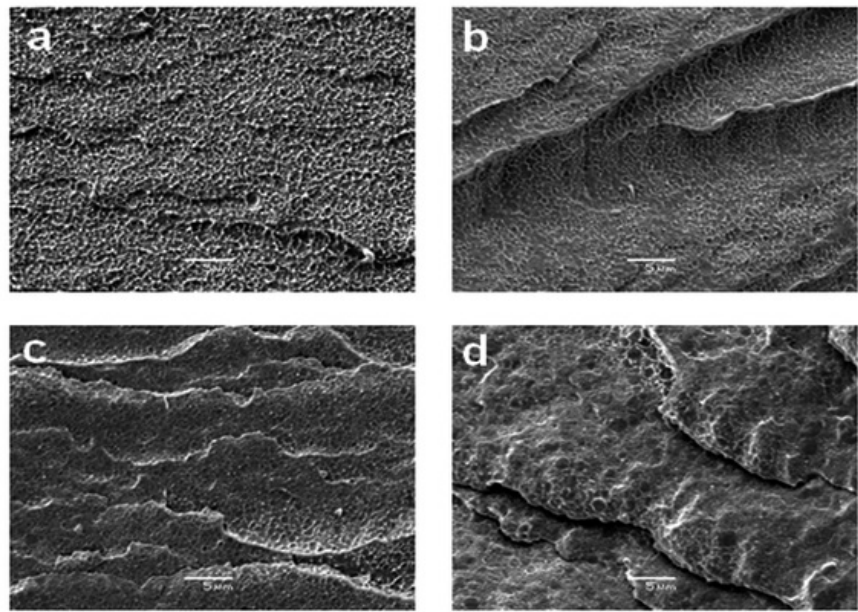

Figure 1: SEM images of fractured surface of neat $\mathrm{rPE}$ and $\mathrm{rPE} / \mathrm{vPP}$ blend samples prepared by compression molding: (a) rPE, (b) rPE/vPP-19, (c) rPE/ vPP-9 and rPE/vPP-5.7. (Scale bar: $5 \mu \mathrm{m}$ )

SEM micrographs of $\mathrm{rPE} /$ and $\mathrm{rPE} / \mathrm{vPP} /$ wood composite (Figure 2) revealed a good dispersion of wood particles in the polymer matrix (no wood agglomerates were observed), which can be attributed to the presence of coupling agents and adequate processing condition used to prepare the composite. In the case of rPE wood composite, obvious gaps between fiber and polymer matrix, large size of holes and wood particle pull-outs were observed, indicating poor interfacial adhesion. On the other hand, composites made with different $\mathrm{rPE} / \mathrm{vPP}$ ratio presented considerably less amount of wood particles 
without polymer matrix coating. As expected, an increasing content of virgin PP in the WPC displayed a lower amount of holes in fractured surfaces. The virgin PP in the composite favors the diffusion of the exposed PP chain of the coupling agent into the polyolefin matrix phase of mainly recycled and virgin PP chains, which contributes to the improvement of interfacial adhesion. There was no visible morphological difference of surfaced fracture of the WPC specimens before and after a long term immersion test (data not shown).
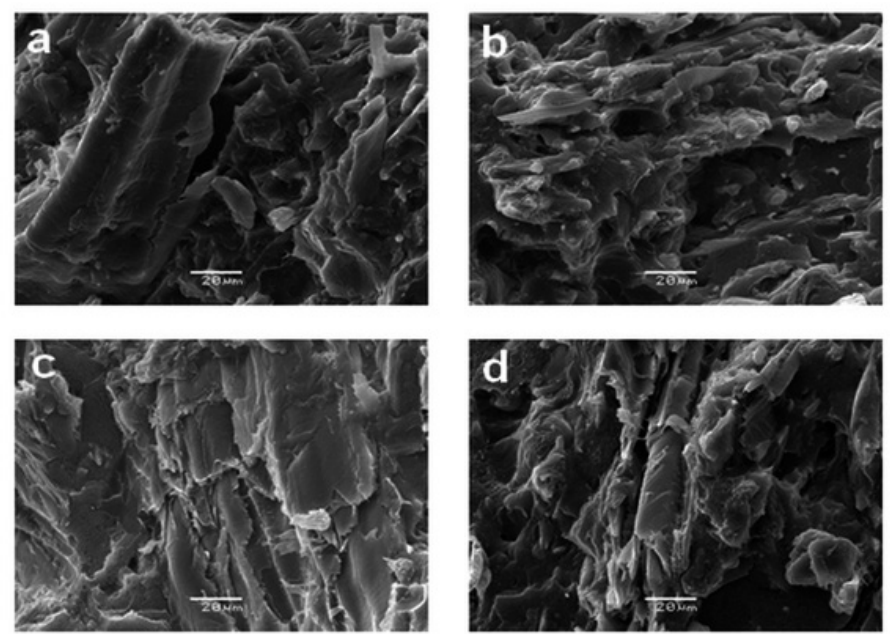

Figure 2: SEM images of fractured surface of WPCs after $2352 \mathrm{~h}$ of immersion in water: (a) WrPE, (b) WrPE/vPP-19, (c) WrPE/vPP-9 and (d) WrPE/vPP-5.7. (Scale bar: $20 \mu \mathrm{m}$ ).
Thermal stability of neat $\mathrm{rPE}, \mathrm{rPE} / \mathrm{vPP}$ blends and their WPCs was analyzed by TGA. Figure 3 shows the TGA and derivative of the TG (DTG) sample curves in the temperature range of $20-640^{\circ} \mathrm{C}$. Temperature at which maximum rate of decomposition occurs $\left(\mathrm{T}_{\mathrm{max}}\right)$ and weight loss associated at this temperature $\left(\mathrm{WL}_{\mathrm{T}_{\max }}\right)$, as well as the onset temperature $\left(\mathrm{T}_{\text {onset }}\right)$ corresponding to each decomposition step of WPCs and temperature at which $5 \%$ of weight loss occurs for $\mathrm{rPE}$ and $\mathrm{rPP} / \mathrm{vPP}$ blends, are summarized in Table III. The TGA curves reveal a one-step decomposition pattern for neat $\mathrm{rPE}$ and $\mathrm{rPE} / \mathrm{vPP}$ blends. The neat $\mathrm{rPE}$ remains stable from room temperature up to $150^{\circ} \mathrm{C}$, with no change of weight of the sample. After a temperature of $150^{\circ} \mathrm{C}$ the rate of decomposition was slow up to $415^{\circ} \mathrm{C}$, with a weight loss of about $3 \%$. Then, the sample started to decompose fast and $\mathrm{T}_{\max }$ was $469^{\circ} \mathrm{C}$. A weight loss of $66 \%$ was recorded at this $\mathrm{T}$. In an inert atmosphere, the thermal degradation of polyethylene is associated with random scission of main polymer chains as well as branching polymers. Both processes occur simultaneously resulting in a single mass loss step. ${ }^{12,13}$

The degradation of $\mathrm{rPE} / \mathrm{vPP}$ blends followed a similar trend as neat rPE. $T_{-5 \%}$ decreased with the increasing of virgin PP content from 4.9 to 14.7 wt.\%. A similar behavior is observed for $\mathrm{T}_{\max }$. The results indicate that the fragmentation of $\mathrm{rPE}$ chains is slightly accelerated by the presence of virgin $\mathrm{PP}$, especially blends with $\mathrm{rPE} / \mathrm{vPP}$ ratio $=5.7$. This behavior is probably due to the higher susceptibility of PP to ultraviolet and oxidative degradation than PE. ${ }^{14}$

Table III: Thermal properties of neat rPE, rPE/virgin PP blends and their WPCs.

\begin{tabular}{|c|c|c|c|c|c|c|c|c|c|}
\hline Sample & $\begin{array}{l}\mathrm{T}_{-5 \%} \\
\left({ }^{\circ} \mathrm{C}\right) \\
\end{array}$ & $\begin{array}{l}\mathrm{T}_{\max } \\
\left({ }^{\circ} \mathrm{C}\right) \\
\end{array}$ & $\begin{array}{c}\mathrm{WL}_{\text {Tmax }} \\
(\%)\end{array}$ & & & & & & \\
\hline $\mathrm{rPE}$ & 425 & 469 & 66.3 & & & & & & \\
\hline rPE/vPP-19 & 421 & 465 & 62.7 & & & & & & \\
\hline rPE/vPP-9 & 420 & 461 & 55.8 & & & & & & \\
\hline \multirow[t]{2}{*}{ rPE/vPP-5.7 } & 393 & 462 & 70.0 & & & & & & \\
\hline & $\begin{array}{l}T_{\text {onset- }} \\
\left({ }^{\circ} \mathrm{C}\right)\end{array}$ & $\begin{array}{l}\mathrm{T}_{\max -1} \\
\left({ }^{\circ} \mathrm{C}\right)\end{array}$ & $\begin{array}{c}W L_{T \max -1} \\
(\%)\end{array}$ & $\begin{array}{l}T_{\text {onset-2 }} \\
\left({ }^{\circ} \mathrm{C}\right)\end{array}$ & $\begin{array}{c}T_{\max -2} \\
\left({ }^{\circ} \mathrm{C}\right)\end{array}$ & $\begin{array}{c}W L_{T \max -2} \\
(\%)\end{array}$ & $\begin{array}{l}\mathrm{T}_{\text {onset-3 }} \\
\left({ }^{\circ} \mathrm{C}\right)\end{array}$ & $\begin{array}{l}T_{\max -3} \\
\left({ }^{\circ} \mathrm{C}\right)\end{array}$ & $\begin{array}{c}\mathrm{WL}_{\mathrm{Tmax}_{\text {max }}} \\
(\%)\end{array}$ \\
\hline WrPE & 31 & 72 & 1.9 & 199 & 352 & 26.6 & 383 & 466 & 71.3 \\
\hline WrPE/vPP-19 & 32 & 71 & 1.7 & 203 & 352 & 28.4 & 385 & 466 & 71.2 \\
\hline WrPE/vPP-9 & 30 & 64 & 2.3 & 210 & 349 & 28.2 & 383 & 463 & 73.3 \\
\hline WrPE/vPP-5.7 & 31 & 68 & 2.2 & 213 & 349 & 26.5 & 385 & 464 & 69.2 \\
\hline
\end{tabular}

$\mathrm{T}_{-50}$ Temperature at which $5 \%$ weight loss occurs in $\mathrm{rPE}$ and $\mathrm{rPE} / \mathrm{vPP}$ blends samples.

$\mathrm{T}_{\text {max }}^{-5 \%}$ Temperature at which maximum rate of decomposition occurs.

WL Weight loss associated at maximum temperature of each decomposition step.

$\mathrm{T}_{\text {onset }}$ The onset temperature corresponding to each decomposition step of WPC.

The weight loss during heating of WPCs occurred in three steps, as shown in Figure 3. Small weight loss (around 3\%) between $30-120^{\circ} \mathrm{C}$ is attributed to the evaporation of water from wood fibers. After $200^{\circ} \mathrm{C}$ the weight loss rate quickly increased and two degradation steps were distinguished, the first one corresponds to the decomposition of wood fiber components such cellulose, hemicellulose, lignin and wood extractives. The maximum rate of decomposition temperature of the second mass-loss step $\left(\mathrm{T}_{\max -2}\right)$ was around $350^{\circ} \mathrm{C}$. The third degradation step between $383-493^{\circ} \mathrm{C}$ is dua to the decomposition of main chains of polyolefin matrix.

TGA curves of WPC samples in nitrogen atmosphere showed slight differences in the onset degradation temperatures corresponding to first $\left(\mathrm{T}_{\text {onset- }-1}\right)$ and third ( $\mathrm{T}_{\text {oncet-3 }-3}$ ) decomposition steps; this did not change systematically by variation of virgin PP content into polymer matrix. However, the second onset degradation temperature $\left(\mathrm{T}_{\text {ont }}\right)$ was shifted to higher temperatures with increasing PP content in WPC samples. The differences in $T_{\text {onet-2 } 2}$ of WPC indicate that virgin PP loading delays the starting of wood fibers degradations. The apparent thermal stability of wood fibers can be attributed to stronger entanglement between PP chains of coupling agent (MAPP) and PP of polymer matrix around the fiber, which results in a diffusion delay of the gaseous degradation products out of the composite.

Mechanical properties of neat rPE, rPE/vPP blends and their WPCs are shown in Figure 4. The incorporation of wood fiber (45 wt.\%) into polymer matrix improved tensile and flexural properties of the studied materials, except for the elongation at breaking. Reinforcing effect of wood fibers is related to their intrinsic properties such as tensile strength, stiffness, chemical inert and dimensional stability. The improvement of tensile and flexural strengths as well as moduli of recycled PE by addition of wood fiber has been previously reported. ${ }^{15,16}$ The major issue in obtaining WPC with superior mechanical properties is an adequate interfacial adhesion between hydrophilic fiber and hydrophobic polymer matrix. In a previous work it was reported, that maleic anhydride modified PP with higher grafting capacity as coupling agent provided significant improvement in mechanical properties of $\mathrm{rPE} /$ wood flour composite. ${ }^{9}$ 

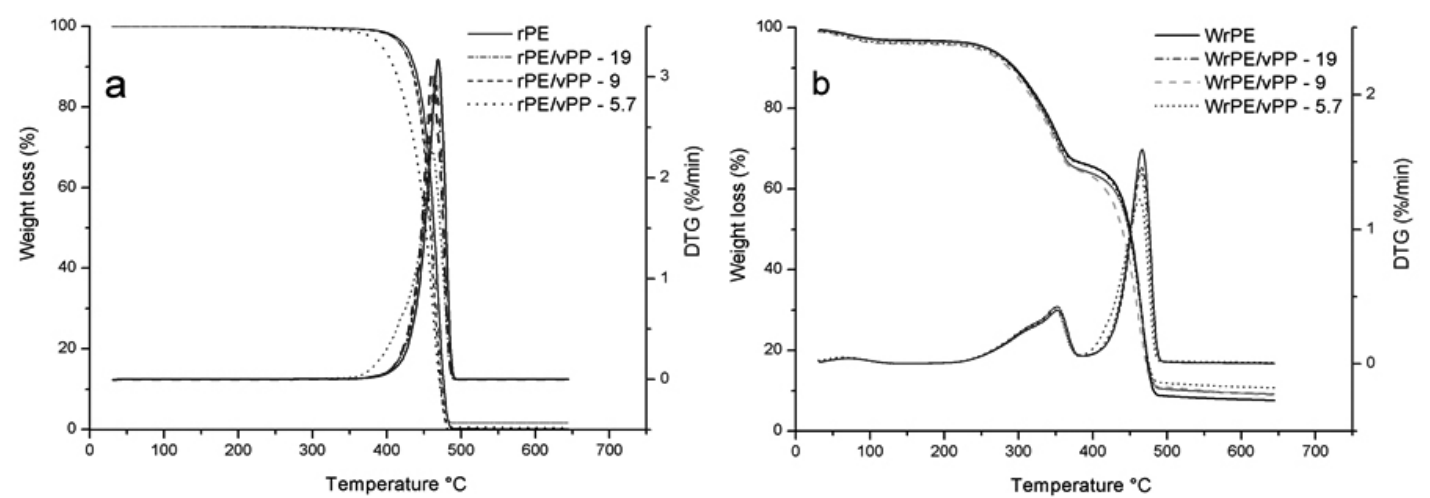

Figure 3: TGA curves of neat rPE and rPE/vPP blends (a) and their WPCs (b).

The effect of $\mathrm{rPE} / \mathrm{vPP}$ ratio on tensile and flexural properties before and after immersion in water of rPE/vPP blends and their WPCs was also analyzed. Before immersion, there was a statistical significant difference among values of tensile and flexural strengths, and flexion modulus for both sample groups: rPE/vPP blends and WPCs made with different rPE/vPP ratio. However, WPC sample made with $\mathrm{rPE} / \mathrm{vPP}$ ratio $=19$ showed the highest increase of tensile and flexural strengths and moduli in relation to polymer matrix $(\mathrm{rPE})$ and $\mathrm{WrPE}$ sample. An increase of about $70 \%$ in tensile and flexural moduli and flexural strength of all WPC samples in relation to polymer matrix was obtained. We can conclude that the addition of small amounts of virgin PP $(\mathrm{rPE} / \mathrm{vPP}=19)$ to the rPE matrix of WPC improves mechanical properties due to heterophasic PP copolymer acting as a reinforcing agent. PP is a stronger but less flexible material than PE, because of a rigid shortly methyl group attached to every second carbon atom of the polymer main chain, which restricts rotation of the chain. ${ }^{17}$ Furthermore, virgin PP chain favors diffusion of the exposed PP chain of the coupling agent into the polyolefin matrix phase. Both factors, in turn, contributed to better mechanical properties of the WrPE/vPP-19 sample.

Phase separation of blend morphology is another factor to be taken into account in the analysis of mechanical properties of studied samples. Weak mechanical properties are associated to higher domain sizes of minor phase and poor interfacial adhesion between polymer constituents of the blends. ${ }^{18}$
Phase separation observed for rPE/vPP blends by SEM could explain why those samples of WPC with higher virgin PP content (WrPE/vPP-9 and WrPE/ vPP-5.7) show lower increase on their mechanical properties.

The mechanical properties of samples after and before immersion displayed similar trends: WPC showed higher tensile and flexural moduli and strengths than polymer matrices (rPE and $\mathrm{rPE} / \mathrm{vPP}$ blends). The mechanical properties of $\mathrm{rPE}$ and $\mathrm{rPE} / \mathrm{vPP}$ blends almost were not affected by immersion, whereas mechanical properties of WPC samples were strongly affected by immersion. In general, the values of tensile and flexural properties of WPC samples significantly decreased after immersion. Thus, tensile modulus and strength decreased around $35 \%$ and $15 \%$ after immersion for WPC, respectively. Similar behavior has been reported by other authors. ${ }^{19,20}$ They postulate that water molecules absorbed by the wood flour not only change the structure and properties of fibers, but also the interface between the polymer matrix and the fibers. Furthermore, water uptake of WPC samples contributes to a loss of compatibilization between fibers and matrix, weakening the interface adhesion. As a result the stress transfer and the load-bearing ability of the composites were deteriorated. The loss in mechanical properties caused by water uptake was higher in WPC samples made with rPE/vPP blends as polymer matrix, due to their higher water uptake during long-term immersion tests (see Figure 5).
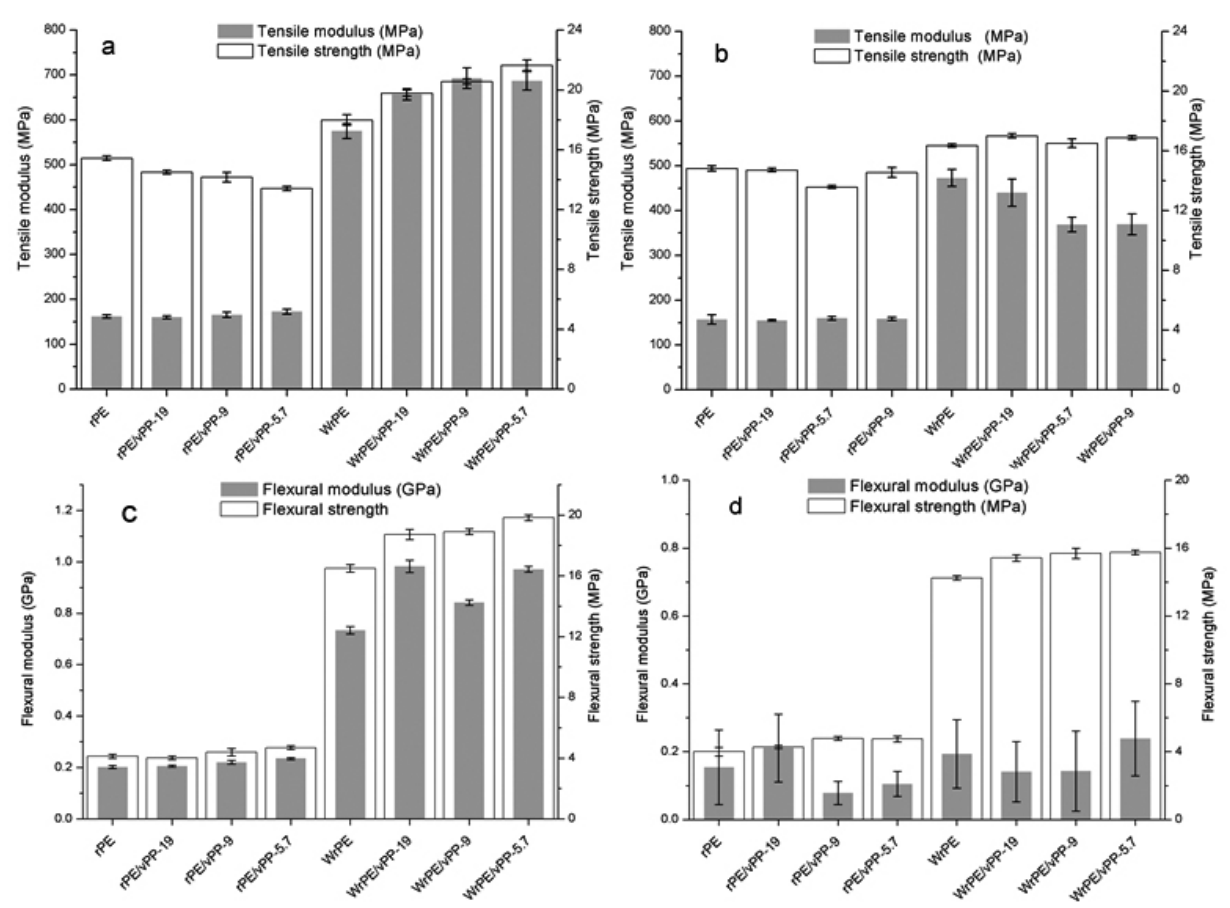

Figure 4: Mechanical properties of neat rPE, rPE/vPP blends and their WPCs after and before of long-immersion test: (a) tensile properties before immersion, (b) tensile properties after immersion, (c) flexural properties before immersion and (d) tensile properties after immersion. 
Water uptake of neat rPE, rPE/vPP blends and their WPCs as a function of the square root of immersion time is illustrated in Figure 5. For all samples, water uptake increased with immersion time up to a saturation point, from which the content of water in the composites remained constant. The water absorption of WPC samples is higher than those of rPE and rPE/vPP blends. The hydrophilic nature of wood flour is required for water uptake in WPCs.
Fibers of Pinus radiate are rich in cellulose and hemicellulose (around 60 wt. $\%)^{21}$, which have free $\mathrm{OH}$-groups that come in contact with water through hydrogen bonding. The water-fiber interaction results in water uptake and weight gain in WPC samples. In addition, microgaps at the fiber and polyolefin matrix interface can contribute to water uptake of the composites because of increased porosity. ${ }^{22}$
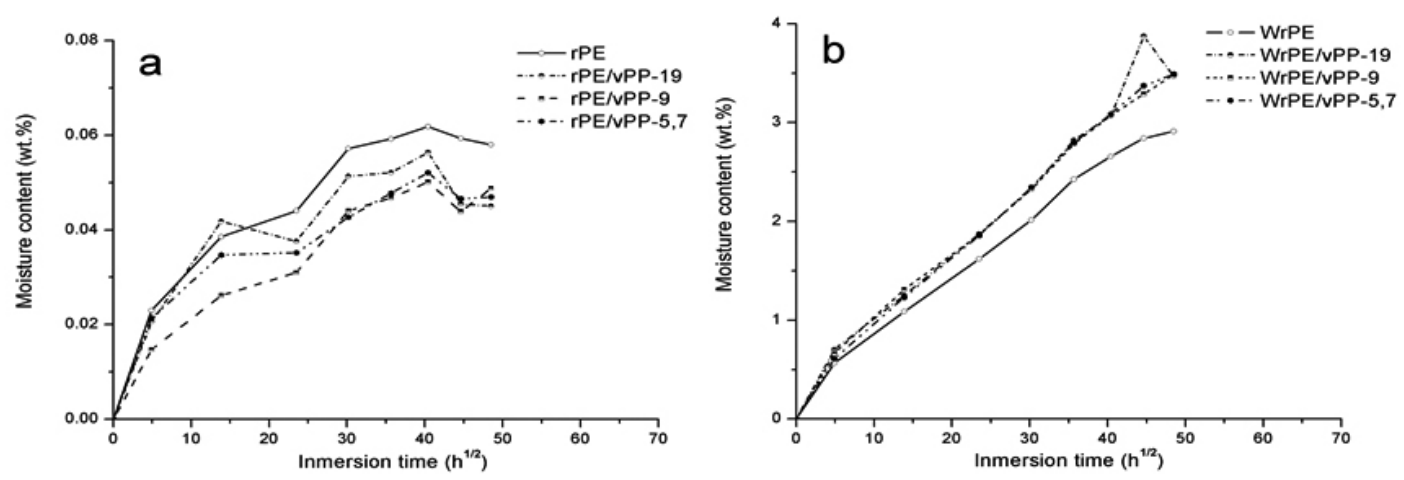

Figure 5: Water uptake (\%) versus the square of time $\left[(\text { hour })^{1 / 2}\right]$ for rPE and rPE/virgin PP blends (a) and their WPCs (b).

The hydrophobic polymeric matrix (rPE or rPE/vPP blends) had no significant water uptake. $\mathrm{rPE} / \mathrm{vPP}$ blends absorbed less water compared to $\mathrm{rPE}$ sample. The lowest water uptake was observed for the rPE/vPP-19 sample, which exhibits better interfacial adhesion between the rPE matrix and virgin $\mathrm{PP}$, as discussed above. However, composites based on the rPE/vPP blends absorbed more water than the WrPE sample. The possible reason is the presence of interfacial voids between $\mathrm{PPE}$ and virgin PP, which allow water to reach the wood fibers. The swelling by water absorption of WPC can lead to microcracking with considerable decreasing of mechanical properties, as has been discussed above. ${ }^{23}$

\section{CONCLUSION}

The incorporation of a virgin heterophasic PP copolymer into the rPE matrix improves the mechanical properties and thermal stability of the composite. WPC made of rPE/vPP blend showed higher values of tensile and flexural moduli and flexural strength than WPC made of rPE. However, the improvement of mechanical properties depends on the rPE/vPP ratio. Composite manufactured with $\mathrm{rPE} / \mathrm{vPP}$ ratio $=19$ showed a higher increase of tensile and flexural strengths and moduli with respect to neat rPE and composite made of rPE. Heterophasic PP copolymer acts as a reinforcing agent and favors diffusion of the exposed PP chain of the coupling agent anchored to wood flour into the polyolefin matrix phase. WPC manufactured with rPE/ $v P P$ ratio $=9$ and 5.7 displayed a slight increase of their mechanical properties. This increment is associated to poor interfacial adhesion between polymer constituents of the blends, factor that is opposed to the reinforcement effects of virgin PP.

TGA results shows that the addition of virgin PP to the polyolefin matrix of WPC delays the starting of wood flour degradation. The apparent thermal stability of wood fibers is attributed to a stronger entanglement between PP chains of coupling agent (MAPP) and PP of polymer matrix around the fiber.

The immersion of WPCs in water adversely affects their mechanical properties, especially of those WPCs manufactured with a $\mathrm{rPE} / \mathrm{vPP}$ polymer matrix. The presence of interfacial voids between $\mathrm{rPE}$ and virgin PP favors water entering into and swelling of the wood fibers.

\section{ACKNOWLEDGMENTS}

The authors thank the CIPA, CONICYT Regional, GORE BÍO BÍO for providing grants, Carmen Pradenas, Johana Sanzana and Lorena Valencia for sample preparation and testing

Funding

This research was supported by CIPA Conicyt-Regional R08C1002 and Programa de Financiamiento Basal para Centros Científicos y Tecnológicos de Excelencia PFB-27

\section{REFERENCES}

1 Ministerio del Medio Ambiente. (2010). Primer reporte del manejo de residuos sólidos en Chile. http://www.sinia.cl/1292/articles-49564 informe final.pdf Accessed 09 August 2013.

2 A. Pérez-Guerrero, J. Lisperguer, F. Orellana. J. Chil. Chem. Soc. 56, 4, (2011)

3 Mundo Acuícola Pesquero. (2012) Una posible solución al problema global del plástico. http://www.mundoacuicola.cl/comun/index.php?mod ulo $=3 \&$ cat $=1 \&$ view $=1 \&$ idnews $=141$ Accessed 27 July 2013

4 K. B. Adhikarya, S. Panga, P. Mark, et al., J. Chem. Eng. 142, 190-198, (2008)

5 C. Clemons, Compos. Part A 41, 1559-1569, (2010) Clemons C (2010)

6 G. Radonjicï, N. Gubeljak, Macromol. Mater. Eng. 287, 122-132, (2002)

7 S. Bertin, J. Robin, Eur. Polym. J. 38, 2255-2264, (2002)

8 H. P. Blom, J. W. The, A. Rudin, J. Appl. Polym. Sci. 70, 2081-2095, (1998)

9 S. Rodríguez-Llamazares, A. Zuñiga, J. Castaño, L. Radovic , J. App. Polym. Sci. 122, (3), 1731-1741, (2011)

10 Y. Mingbo, W. Ke, Y. Lin, et. al., Plast. Rubber. Compos. 32 (1), 27-31, (2003)

11 J. Su, J. Zhang, J. Elastom. Plast. Epub ahead of print 23 January 23, (2013)

12 A. N. Shebani, A. J. Van Reenen, M. Meincken, J. Compos. Mater. 43, 1305-1318, (2009)

13 P. K. Roy, P. Surekha, C. Rajagopal, et al., Express. Polym. Lett. 4 (1), 208-216, (2007)

14 A. C. Y. Wong, F. Lam, Polym. Test. 21, 691-696, (2002)

15 A. Viksne, L. Rence, R. Berzina, Mech. Compos. Mater. 40 (2), 169$178,(2004)$

16 K. Redighieri, D. Costa, Polimeros 18, 5-11, (2008)

17 E. Sihama, F. Abdullkhaliq, H. Alyaa, Mod. Appl. Sci. 7 (3), 33-42, (2013)

18 D. Feldman, J. Macromol. Sci. Pure Part A 42, 587-605, (2005)

19 A. Espert, F. Vilaplana, S. Karlsson, Compos. Part A-Appl. Sci. 35, 1267$1276,(2004)$

20 N. Stark, L. M. Matuana, C. Clemons, J. Appl. Polym. Sci. 93, 1021-1030, (2004)

21 A. Berrocal, J. Baeza, J. Rodríguez, et al., J. Chil. Chem. Soc. 49 (3), 251256, (2004)

22 T.T. Law, Z. A. Mohd Ishak, J. Appl. Polym. Sci. 120, 563-572, (2011)

23 A. Arbelaiz, B. Fernández, J. A. Ramos, et al., Compos. Sci. Technol. 65, $1582-1592,(2005)$ 